\title{
Multicriteria Decision Making (MCDM) for evaluation of different transportation alternatives: A case of Rawalpindi bypass Pakistan
}

\section{Malik Kamran Shakir ${ }^{1}$ (D), Muhammad Bilal Khurshid ${ }^{2}$, Jawed Iqbal ${ }^{3}$ (D), Muhammad Adeel ${ }^{2}$}

\author{
${ }^{1}$ NUST Institute of Civil Engineering, School of Civil \& Environmental Engineering (SCEE), \\ National University of Sciences \& Technology (NUST), Islamabad, Pakistan, \\ Department of Civil Engineering \\ ${ }^{2}$ Military College of Engineering, National University of Sciences \& Technology (NUST) Islamabad, \\ Risalpur Campus, KPK, Pakistan-24080 \\ Department of Transportation Engineering \\ ${ }^{3}$ National Institute of Transportation, National University of Sciences \& Technology (NUST) Islamabad \\ Department of Transportation Engineering
}

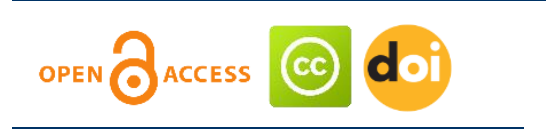

\section{Article history:}

Received: December 12,

2017

1st Revision: September 07,

2018

Accepted: November 29,

2018

\section{DOI:}

10.14254/jsdtl.2018.3-3.3

\begin{abstract}
Safe, efficient and user-friendly transportation of people and goods have been a premier point of concern for all the developed and the developing countries around the globe. National Highway N-5 or GT road is the most important highway link in Pakistan. It carries about $80 \%$ of the country freight traffic. When this heavy traffic passes through the twin cities of Rawalpindi and Islamabad, it causes congestion and environmental hazards particularly in business centers of Rawalpindi city. Because of this heavy traffic volume passing through the cities situated along $\mathrm{N}-5$, bypasses to all of them have been provided however, Rawalpindi is the only city along N5 which is still without a bypass. A bypass to Rawalpindi city is, therefore, inevitable. Besides this, the Bypass will also provide a short access to the traffic on the Motorway (M2) destined for the western part of Rawalpindi. For this research work, Rawalpindi Bypass is taken as a hypothetical scenario and is evaluated for its benefits. Besides addition to the networks of highways across Pakistan, this bypass has many other benefits which include a decrease in congestion from Islamabad and Rawalpindi main arteries (ISB Highway and IJP Road) that results in travel time savings, vehicle operating cost savings, safety savings, and reduced air pollution. This research aims to produce an engineering and scientific comparison of various costs and benefits associated with the road agency and users about the construction of an alternative. The Project involves transportation demand estimation on different segments of the National and Arterial roads, Project Costs, travel time savings, safety saving, vehicle operating cost savings, economic efficiency analysis, Air quality impact and multi criterion transportation decision making. The transportation decision making process usually involves the evaluation of effectiveness and efficiency of an alternative decision
\end{abstract}

Corresponding author: Malik Kamran Shakir

E-mail: kamranshakir@nice.nust.edu.pk

This open access article is distributed under a Creative Commons Attribution (CC-BY) 4.0 license. 
with respect to a base case DO-NOTHING Scenario. The authors have taken the existing roadway structure with no improvements as DONOTHING Scenario, whereas the construction of Rawalpindi Bypass $(60 \mathrm{~km})$ with 2 lanes in each direction is taken as Alternative B and Rawalpindi Bypass $(51 \mathrm{~km})$ as Alternative C. Multi criteria decision making technique is used for decision because of multiple options with different dimensions, both monetary and non-monetary. Basing of MCDM this study recommends Alternative C (51 km) for Rawalpindi Bypass.

Keywords: Rawalpindi bypass, multi criteria decision making, travel time savings, safety savings, vehicle operating cost savings, air quality impact.

\section{Introduction}

The core of transportation decision making is the evaluation of transportation projects and programs in the context of available funding. For this reason, the principles and procedures of transportation project evaluation and programming are of interest to transportation engineers and planners, transportation agency administrators, facility managers and service providers, environmental groups and the general public. This is a critical issue for governments everywhere. Each year, several trillions of dollars are invested worldwide in transportation facilities with a view to enhancing transportation system mobility, security, and safety, and to spurring economic development while minimizing environmental and other adverse impacts. Same is the case within Pakistan. In most countries, the sheer size of existing transportation assets and investment levels, coupled with the multiplicity of transportation system impacts and stakeholders, necessitates a comprehensive, yet integrated and consistent approach to evaluating such impacts. The new millennium is characterized by continued growth in commercial and personal travel demand, and transportation agencies and providers strive to keep their assets in acceptable condition so as to offer desirable levels of service in the most cost-effective manner and within available resources. Consistent with such efforts is the need for best-practices evaluation and monitoring of the expected impacts of alternative investment decisions, policies, and other stimuli on the operations of existing or planned transportation systems and their environments.

The 24 hrs traffic counts at Rawat along N5 in 2003 were more than 22,000 vehicles and in year 2015 it increased to more than 50,000 according to the survey of national highway authority Pakistan. It is because of this huge amount of traffic passing through the cities situated along N-5 that bypasses to all of them have been provided. Rawalpindi is the city still without a bypass. More than 6,000 trucks pass through the city in 24 hours. This volume of truck traffic seriously affects environment of the city. A bypass to Rawalpindi city is, therefore, inevitable. Besides this, the Bypass will also provide a short access to the traffic on the Motorway (M2) destined for the western part of Rawalpindi. Enroute, the Bypass will connect, Rawat-Chakbeli road, Adyala Road and Chakri Road in Rawalpindi and TarnolFatehjang road in Islamabad. Absence of bypass results in mixed traffic, traffic Congestion, grid locks, environmental hazards (noise and air pollution) and traffic safety issues. During study, it was revealed that the intra city traffic is compelled to pass through the city of Islamabad and Rawalpindi and this traffic combined with the local slow-moving vehicles results in high traffic congestion and traffic management problems usually on IJP road Rawalpindi and Islamabad expressway. The provision of Rawalpindi bypass will help reduce the traffic pressure in twin cities. The main objectives of this research work are to find the best alternative for Rawalpindi Bypass in term of construction cost and user benefits by carrying out multi criteria decision making (MCDM). The Project involves Project Cost estimations of Rawalpindi Bypass, travel time savings, safety saving, vehicle operating cost savings, economic efficiency analysis, Air quality impact and multi criterion transportation decision making. Existing road way structure with no improvements taken as DO-NOTHING Scenario, whereas the construction of Rawalpindi Bypass $(60 \mathrm{~km})$ with 2 lanes in each direction is taken as Alternative B and Rawalpindi Bypass $(51 \mathrm{~km})$ as Alternative C. Existing scenario shows the existing traffic pattern distributed along the N5 and Islamabad highway. Heavy traffic which is coming from Punjab cities and 
from Peshawar uses N5, at Pirwadai flyover the heavy traffic is diverted towards IJP road and from Faizabad interchange the traffic it diverts onto Islamabad Highway. Figure 1 is showing existing or donothing scenario.

Figure 1: Existing Scenario / Do nothing scenario

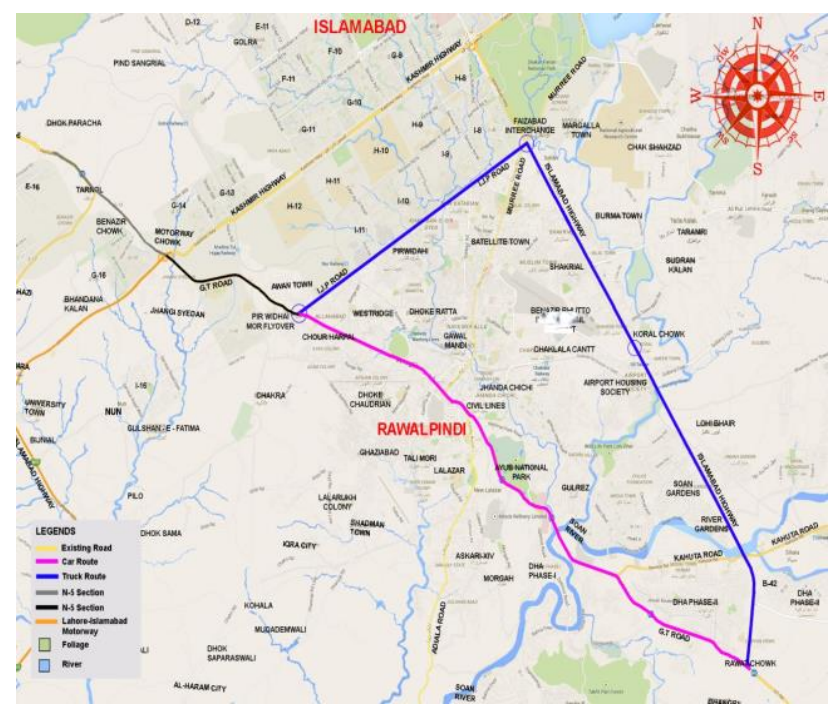

For alternative 1 the start point of Rawalpindi Bypass project is $5 \mathrm{~km}$ short of Rawat, which is an important junction on the N-5 and terminates at Nicolson Monument Islamabad at junction of N5. Total length of alignment is $60 \mathrm{~km}$. Figure 2 is showing alignment \# 1

\section{Figure 2: Alignment \# 1 for the proposed Rawalpindi Bypass $(60 \mathrm{~km})$}

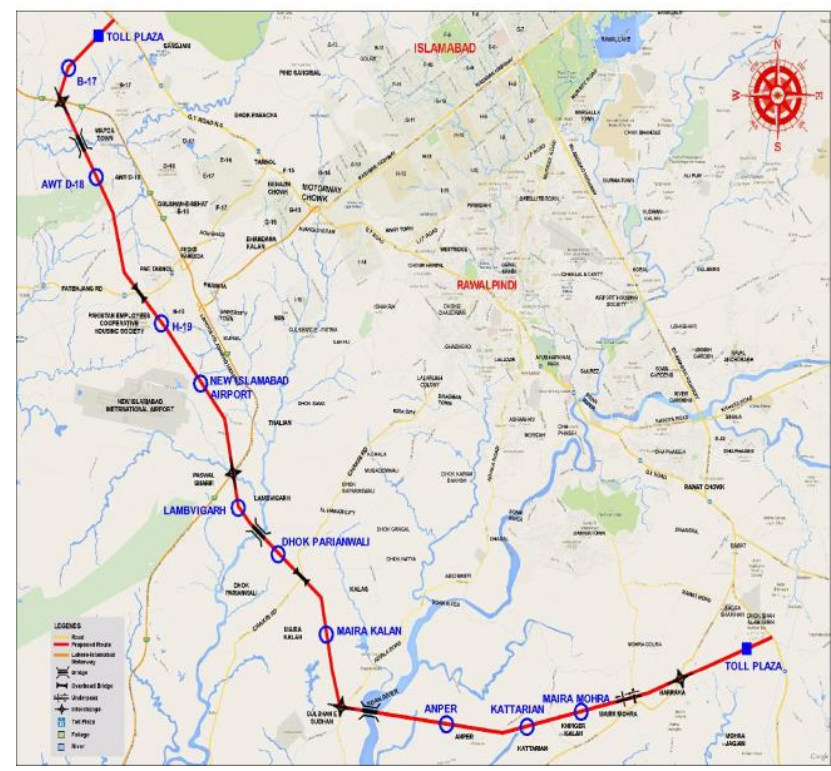

For Alternative \# 2 the start point of Rawalpindi Bypass project is $1 \mathrm{Km}$ short of Rawat, which is an important junction on the N-5 and terminates at sector B17 Islamabad at junction of N5. Total length of alignment is $51 \mathrm{~km}$. Figure 3 showing alignment \# 2 . 
Figure 3: Alignment \# 2 for the proposed Rawalpindi Bypass (51 km)

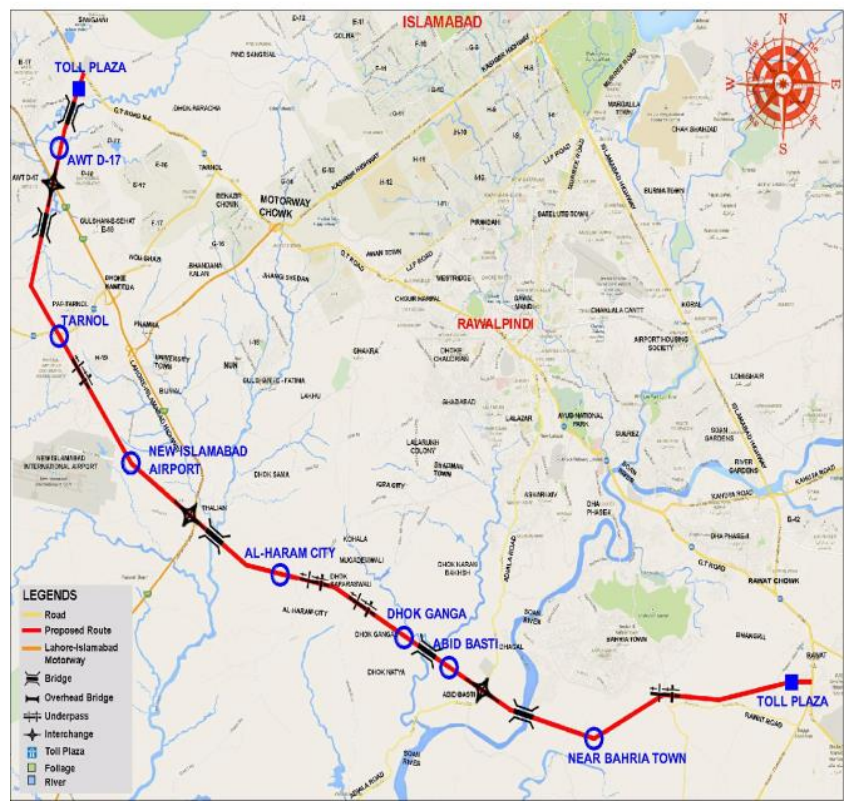

\section{Literature Review}

\subsection{Travel Time Savings}

Enhancements to a transportation system are often expected to yield increased travel speed or decreased waiting or transfer times, and consequently, reduced travel time. The savings associated with reduced travel time typically constitute the largest component of transportation user benefits. In this part of research study is been carried out on issues associated with travel time as a transportation performance measure and methodologies for the assessment of travel-time amounts and unit monetary values for the purpose of evaluating the travel-time impacts of transportation projects. Given that the values of travel time vary by certain attributes of the trip and the trip-maker, it is important to establish the travel-time amount. The overall framework for assessing travel-time impacts involves the estimation of travel-time amounts, travel-time values, and overall savings in travel-time costs.

\subsection{Safety Savings}

Transportation projects generally have a direct or indirect safety component that reduces the rate or severity of crashes. As such, safety enhancement is considered a key aspect of user benefits associated with physical or policy changes in a transportation system. The economic cost of transportation crashes, which is borne by individuals, insurance companies, and government, consists of loss of market productivity, property damage, loss of household productivity and workplace costs. The most basic unit for measuring transportation safety is a crash. A crash can be defined as a collision involving at least one moving transportation vehicle (car, truck, plane, boat, railcar, etc.) and another vehicle or object. Transportation crashes are typically caused by factors such as driver, pilot, or operator error, mechanical failure, and poor design of the guide way, roadway, waterway, or runway. A crash can also involve non- collision off the transportation path, such as a vehicle rollover. Engineering factors involved in a road crash are as shown in Figure 4. 
Figure 4: Engineering Factors of Highway Transportation Crashes

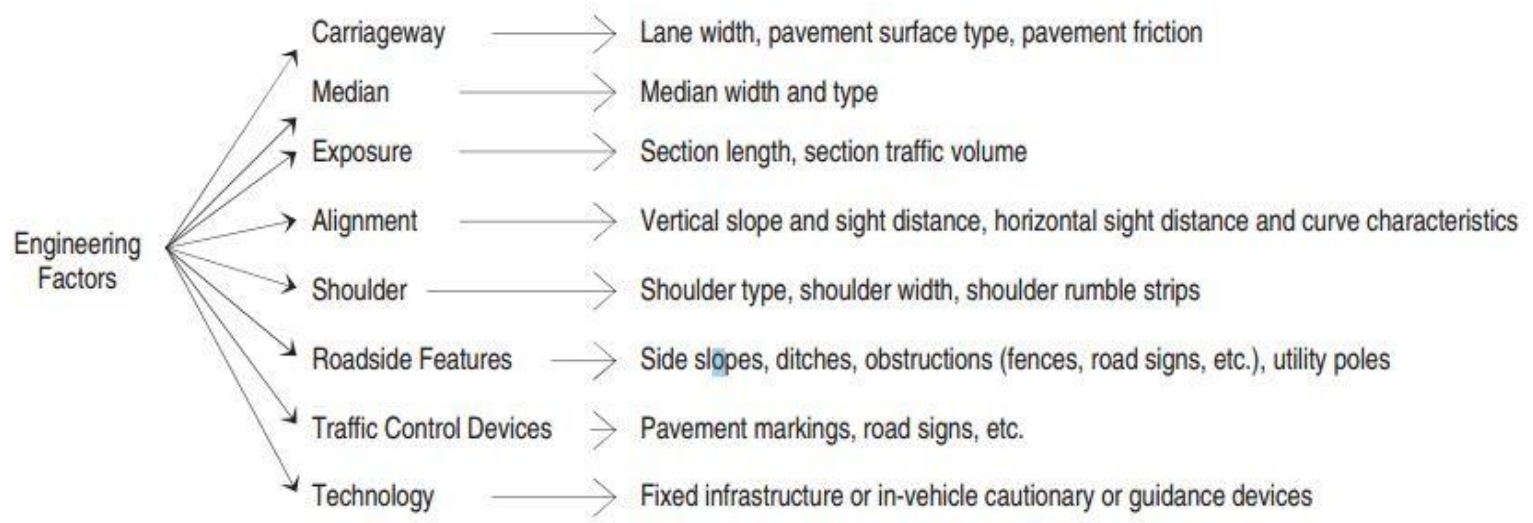

Source: Reprinted from Transportation Decision Making: Principles of Project Evaluation and Programming (P. 103) by Sinha, C Kumares, Samuel Labi, 2007, John Wiley \& Sons. Inc.

\subsubsection{KABCO Scale}

KABCO Injury Scale Established by the American National Standards Institute, the KABCO injury scale (Table 1) is designed for police coding of crash details at a crash scene. The coding does not require medical expertise the police officer at the crash scene assesses the sustained injuries and assigns a code depending on the level of severity. The KABCO system has faced some criticism because it does not always classify injuries classification in a consistent manner (e.g. the code assigns equal severity to a broken arm and a severed spinal cord). Therefore, in a bid to reduce the variability in reporting, the National Highway Traffic Safety Administration (NHTSA) wish to use another scale rather than KABCO scales to describe transportation injuries. But for our project we have used KABCO scale.

Table 1: KABCO Scale for Crash Severity

\begin{tabular}{|c|c|c|}
\hline Code & Severity & Injury Description \\
\hline $\mathrm{K}$ & Fatal & Any injury that results in death within 30 days of crash occurrence \\
\hline A & Incapacitating & $\begin{array}{l}\text { Any injury other than a fatal injury which prevents the injured person } \\
\text { from walking, driving, or normally continuing the activities the } \\
\text { person was capable of performing before the injury occurred (e.g., } \\
\text { severe lacerations, broken limbs, damaged skull) }\end{array}$ \\
\hline B & Injury evident & $\begin{array}{l}\text { Any injury other than a fatal injury or an incapacitating injury that is } \\
\text { evident to observers at the scene of the crash in which the injury } \\
\text { occurred (e.g., abrasions, bruises, minor cuts) }\end{array}$ \\
\hline $\mathrm{C}$ & Injury possible & $\begin{array}{l}\text { Any injury reported that is not a fatal, incapacitating, or } \\
\text { nonincapacitating evident injury (e.g., pain, nausea, hysteria) }\end{array}$ \\
\hline $\mathrm{O}$ & Property damage only & $\begin{array}{l}\text { Property damage to property that reduces the monetary value of that } \\
\text { property }\end{array}$ \\
\hline
\end{tabular}

Source: https://safety.fhwa.dot.gov

\subsection{Vehicle Operating Cost (VOC) Savings}

Vehicle costs are direct expenses that comprise the costs of vehicle ownership (fixed) and vehicle operation (variable). The latter category, typically referred to as vehicle operating costs (VOC's), varies with vehicle use and is typically expressed in cents per mile traveled by a vehicle. For most transportation modes, VOC involves energy use, tires, maintenance, repairs, and mileage dependent depreciation (Sinha et al, 2008). Fixed vehicle costs are those that are largely independent of vehicle use and are generally unaffected by transportation improvements; examples are insurance costs, time 
dependent depreciation, financing and storage. Such costs are therefore typically excluded from VOC impact evaluation of projects. VOC savings or benefits of a transportation improvement or intervention simply refer to the reduction in vehicle operating costs compared to an existing situation or a base-case alternative. For area wide or corridor-level projects involving multimodal systems, an improvement in any part of the system can affect VOCs of the other parts or other modes. For example, service improvement in commuter rail or provision of a bus rapid transit along a corridor can affect the level of service on highway facilities in the same corridor because the shift of some travelers from automobile to transit would lead to improved highway level of service due to reduced congestion and thus, lower vehicle operating costs at the highway section. Figure 5 shows the factor affecting VOC (Sinha et al., 2008).

\section{Figure 5: Factors Affecting Highway Vehicle Operating Cost}

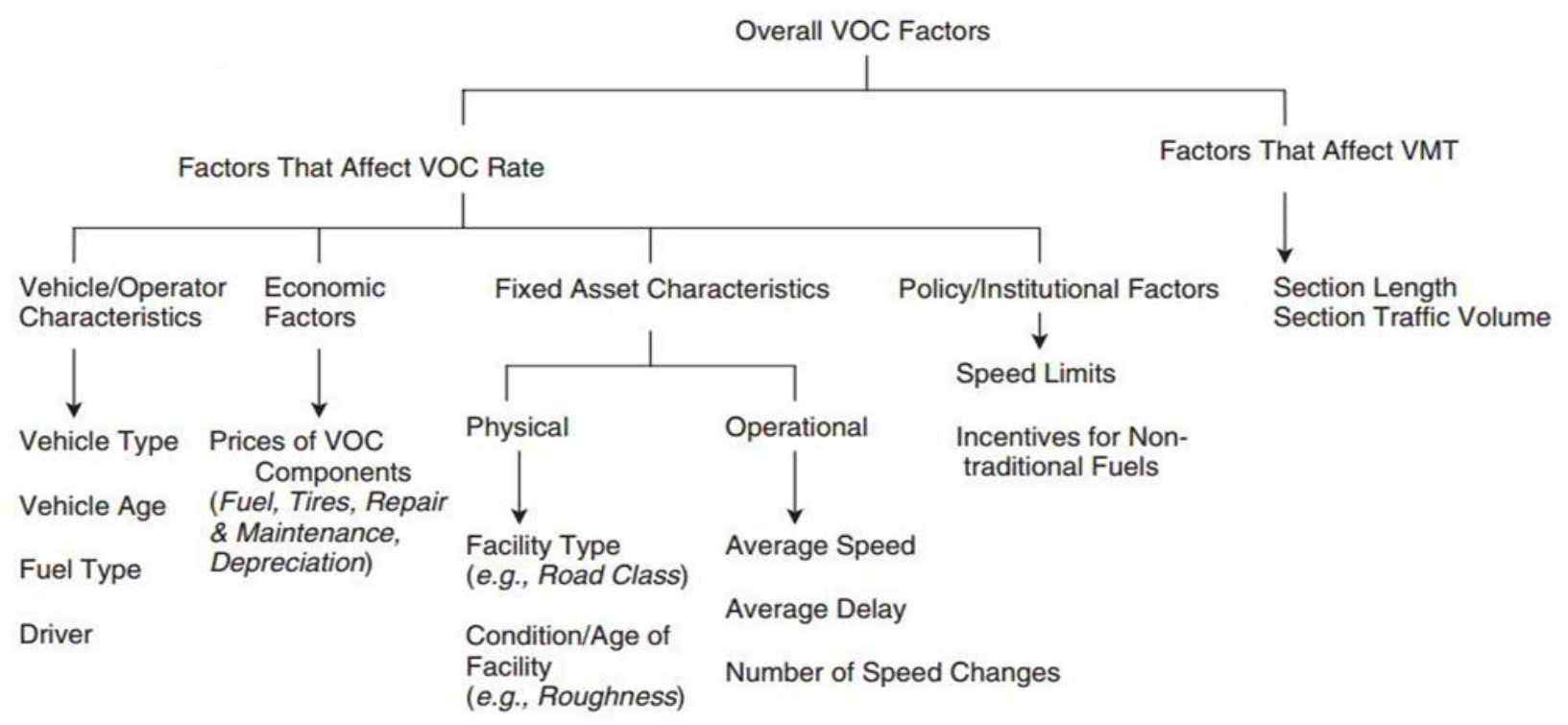

Source: Sinha et al, 2008

\subsubsection{Hepbrun Model}

Hepburn developed a VOC model in 1994 for urban roadways that considers the sum of four VOC components (tires, vehicle depreciation, maintenance, and fuel) as a function of two VOC factors: speed and vehicle class. The model is particularly useful for evaluating VOC impacts of transportation interventions that mostly yield a change in average operating speeds or policies that cause a shift in vehicle class distribution. The Hepburn function is as follows (S Hepburn, 1994):

For "low" average travel speeds $(<50 \mathrm{mph})$ :

$$
V O C=C+\frac{D}{S}
$$

For "high" average travel speeds (> $50 \mathrm{mph})$ :

$$
V O C=a_{o}+a_{1} S+a S^{2}
$$

where VOC (cents/mile),

$\mathrm{S}$ - speed (mph)

and $C, D, a_{0}, a_{1}$, and $a_{2}$ are coefficients that are functions of vehicle class.

\subsection{Air Quality Impact}

Transportation or "mobile" sources of air pollution, particularly motor vehicles, are a primary source of local carbon monoxide problems and are considered the main cause of excess regional 
photochemical oxidant concentrations. Transportation vehicles typically emit carbon monoxide, nitrogen oxides, small particulate matter, and other toxic substances that can cause health problems when inhaled. Air pollution also has adverse effects on forests, lakes, and rivers. The contribution of transportation vehicle use to global warming remains a cause for much concern as anthropogenic impacts on the upper atmosphere become increasingly evident.

Airports, for instance, are a major source of local violations of ambient carbon monoxide standards and contribute to regional photochemical oxidant problems. In the current era, rail travel is increasingly being powered by electricity and is therefore typically not associated with significant air pollution, except in cases where the source of rail energy generation is associated with significant pollution, such as coal-based electrical power generation.

\subsection{Multi Criterion Decision Making}

In multi criteria decision making, a key step is the explicit or implicit assignment of relative weights to each performance criterion (Ling Xu et al, 2001) to reflect its importance compared to other criteria; for example, to what extent is safety improvement more important than travel-time reduction, increase in facility condition, vehicle operating cost decrease, increased economic development, improved aesthetics, and so on? The following methods can be used to establish the weights:

- Equal Weighting

- Direct Weighting

- Regression-Based Observer-Derived Weighting

- Delphi Approach

- Gamble Method

- Pairwise Comparison

- Value Swinging.

\subsubsection{Pairwise Comparison of the Performance Criteria:}

Pairwise comparison is the technique used in this study to establish weights for the performance criteria. Weighting can be carried out using pairwise comparison of performance criteria, and a common tool for doing this is the analytical hierarchy process (AHP). AHP establishes the weights of performance criteria by allowing the survey respondent (decision maker) to consider objective and subjective factors in assessing the relative importance of each criterion (Saaty, 1977). Using AHP, decision makers can develop weights that reflect their experience and knowledge in a natural and intuitive manner. In AHP, complex structures representing performance criteria are organized in hierarchical clusters facilitate pairwise comparisons between the criteria at each hierarchical level to estimate their relative weights. Pairwise comparisons between two performance criteria $\mathrm{i}$ and $\mathrm{j}$ can be represented by using the reciprocal matrix:

$$
\begin{gathered}
a_{i j}=a_{i k} \times a_{k j}, \\
\text { for } i, j=1,2, \ldots, n
\end{gathered}
$$

Such situations, which may result in the development of an inconsistent reciprocal matrix, generally arise when the entries $a_{i j}$ are based on subjective judgments of the survey respondents (decision makers) rather than on exact measurements. As a result, the relationship is modified as follows:

$$
A w=\lambda x w
$$

Where $\lambda$ is a set of eigenvalues of the matrix $A$ such that $\sum \lambda_{i}=n$.

When the relationship in equation holds and the reciprocal matrix is perfectly consistent, all the eigenvalues $\left(\lambda_{i}\right)$ are zero with the exception of one which is equal to $n$ (the largest eigenvalue of the matrix in this scenario). On the other hand, when the reciprocal matrix is inconsistent (due to subjectivity of judgments), the largest eigen value, $\lambda_{\max }$, is close to $\mathrm{n}$, and the remaining eigenvalues are close to zero. Under these circumstances, to determine a unique set of relative weights, a vector w has to be found that satisfies the following relationship: 


$$
A w=\lambda_{\max } x w
$$

The relative weights are computed as the components of the normalized eigenvector associated with the largest eigen value of their comparison matrix. The eigen vector of the reciprocal matrix can be computed using vector algebra, numerical methods to yield the relative weights (Ling Xu et al, 2001).

Consistency checks, an important step in AHP, assess the degree of randomness in the judgments used to develop the reciprocal matrix. The deviation of $\lambda_{\max }$ from $\mathrm{n}$ is used as a measure of the consistency with the reciprocal matrix developed (Ling Xu et al, 2001). The logical consistency of the pairwise comparisons can be measured using the consistency index (CI), which is defined as:

$$
C R=\frac{C I}{R I}=\frac{\lambda_{\max }-n}{(n-1)}
$$

The consistency index is then compared with the average consistency index of randomly generated reciprocal matrices (referred to as the random index, RI) to determine the level of inconsistency in the survey responses. Table 3 shows the random indices for matrices of order 1 through 10 (Saaty, 1994).

Table. 1: Relationship between Matrix Order and Average Random Index

\begin{tabular}{cc} 
Order of matrix $(\boldsymbol{n})$ & Average Random Index \\
\hline 1 & 0.00 \\
2 & 0.00 \\
3 & 0.58 \\
4 & 0.90 \\
5 & 1.12 \\
6 & 1.24 \\
7 & 1.32 \\
8 & 1.41 \\
9 & 1.45 \\
10 & 1.49 \\
\hline
\end{tabular}

The overall consistency of AHP judgments can be determined using the consistency ratio (CR), which is computed as follows:

$$
C R=\frac{C I}{R I}=\frac{\lambda_{\max }-n}{(n-1)(R I)}
$$

A consistency ratio of 0.1 or lower is considered acceptable (Saaty, 1994). If the ratio exceeds 0.1 , then the judgments are considered random and the reciprocal matrix should be recomputed.

In summary, the AHP process for weighting involves the following steps:

1. Constructing a pairwise comparison matrix

2. Estimating the value of the eigenvector that reflects the relative weights

3. Checking for consistency AHP can also be used to synthesize judgments and estimate priorities for alternatives.

\section{Research Methods}

Multiple criteria decision making (MCDM) refers to making decisions in the presence of multiple, usually conflicting, criteria. MCDM problems are common in everyday life. The authors have evaluated project cost, travel time benefits, safety benefits, vehicle operating cost benefits and reduced emissions. Based on these performance criteria different alternatives are evaluated and then a better alternative is selected through multi criteria analysis.

\subsection{Cost Estimation}

The second part and the most important part of our assigned project is the cost estimation. The cost for alternatives is calculated using the engineer's estimate of E35 Hasanabdal to Havelian while following the NHA CSR 2011 specifications. All the costs are calculated as an average cost after considering the costs of E35 Hasanabdal to Havelian expressway. Table 2 shows the aggregate costs of 
different categories of road construction. All costs are converted to the year 2015 using CPI indices i.e. $C P I_{2011}=202.32 \& C P I_{2015}=233$. Two Interchanges data were used for the estimation of cost of Interchanges on the proposed Alignment. Those interchanges were Zero Point Interchange which was completed in year 2011 and Faizabad Interchange which was constructed in the year 1998. Their construction cost was taken as in the relative year of its completion. Table 4 is showing the aggregate costs of each construction activity.

\begin{tabular}{lccc}
$\begin{array}{l}\text { Table 2: Aggregate Costs } \\
\text { Type of Construction/ } \\
\text { Structures }\end{array}$ & $\begin{array}{c}\text { Cost 2011 } \\
\text { (Rs. Millions) }\end{array}$ & $\begin{array}{c}\text { Cost 2015 } \\
\text { (Rs. Millions) }\end{array}$ & Units \\
\hline Pavement Construction & 37.00 & 42.55 & Per Lane per km \\
Interchanges & 2395 & 2755 & Per Interchange \\
Toll Plazas \& Weight Stations & 115.00 & 132.25 & Per Toll Plaza \\
Bridges & 1.760 & 2.024 & Per Linear Meter \\
Underpasses & 1.050 & 1.20 & Per Linear Meter \\
Ancillary Works & 5.80 & 6.67 & Per Lane per km \\
Structures CCulverts/Retaining Walls and & 12.700 & 14.605 & Per Lane per km \\
Drainage \& Erosion Works & & & \\
\hline
\end{tabular}

\section{Proposed Rawalpindi Bypass Cost Estimation}

Using Table 3 costs for proposed alignments for Rawalpindi Bypass have been calculated. Proposed alignments are 2 lanes on each side. The lengths and other characteristics of alignments are shown in Table 3. Table 3 and 4 are showing overall construction costs of both alignments. Total cost for proposed bypass is divided into two main categories i.e. land acquisition and road construction cost.

\section{Table 3: Proposed Alignment \# 1 (60 Km)}

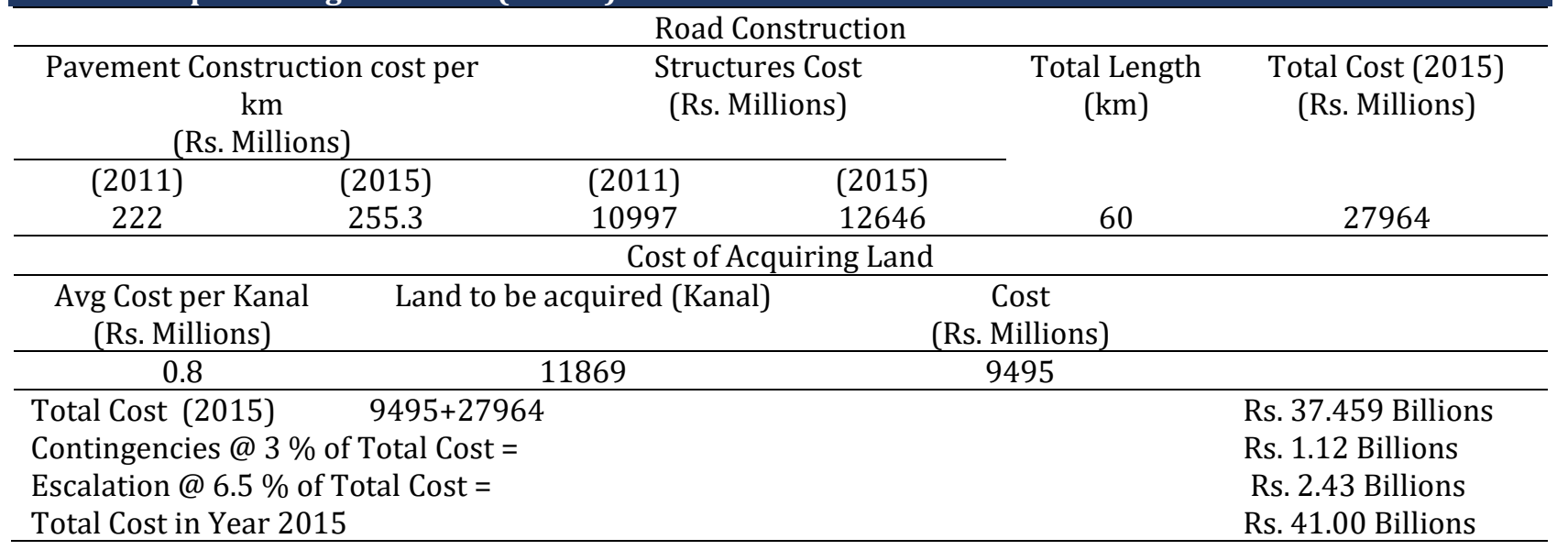

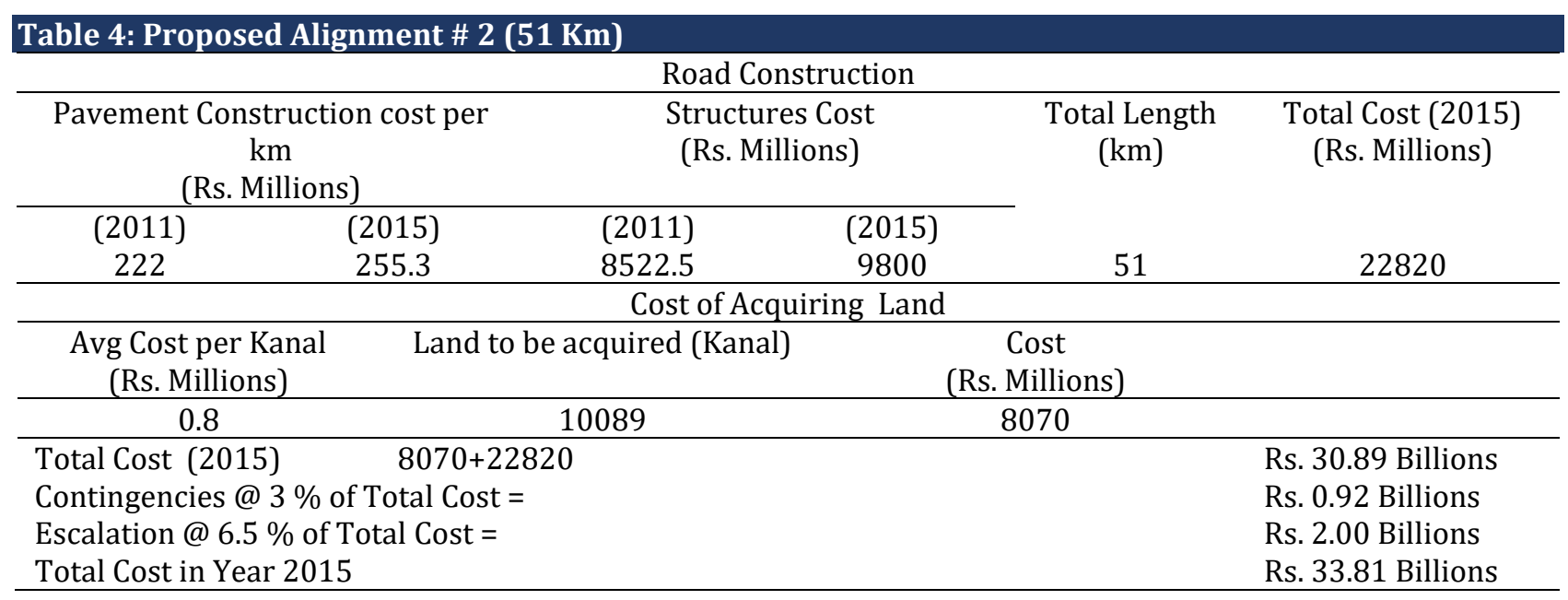




\section{Analysis and Results Discussion}

\subsection{Travel Time Benefits}

For travel time benefits a present case scenario (existing situation) and an alternative scenario (transportation improvement due to intervention) are taken for analysis purposes. Currently, 56500 vehicles pass through N5 that includes 70\% non-commercial and 30\% commercial vehicles. The commercial vehicles that are mostly the trucks are diverted to IJP road which passes through Faizabad Interchange joining the Islamabad Expressway and travel to Rawat. In bypass case scenario out of total AADT 17,000 which includes 9000 Trucks and 8000 cars are diverted on bypass while the rest is traveling on the existing route. There will be no trucks traveling on the existing routes as all the trucks are diverted on bypass. The existing road is divided into numbers of sections. Travel time before and after intervention. HCM method is used for calculations of speed. These calculations are made after making some assumptions about free flow speed for different segments taken for analysis. The unit travel time costs are converted to year 2015 using CPI index for year 2014 \& 2015. Unit travel time cost for cars is taken as 320 PKR and for trucks PKR 222. For travel time savings equation from HCM is used. Detail results are shown in Figure 6.

Figure 6: Travel Time Savings

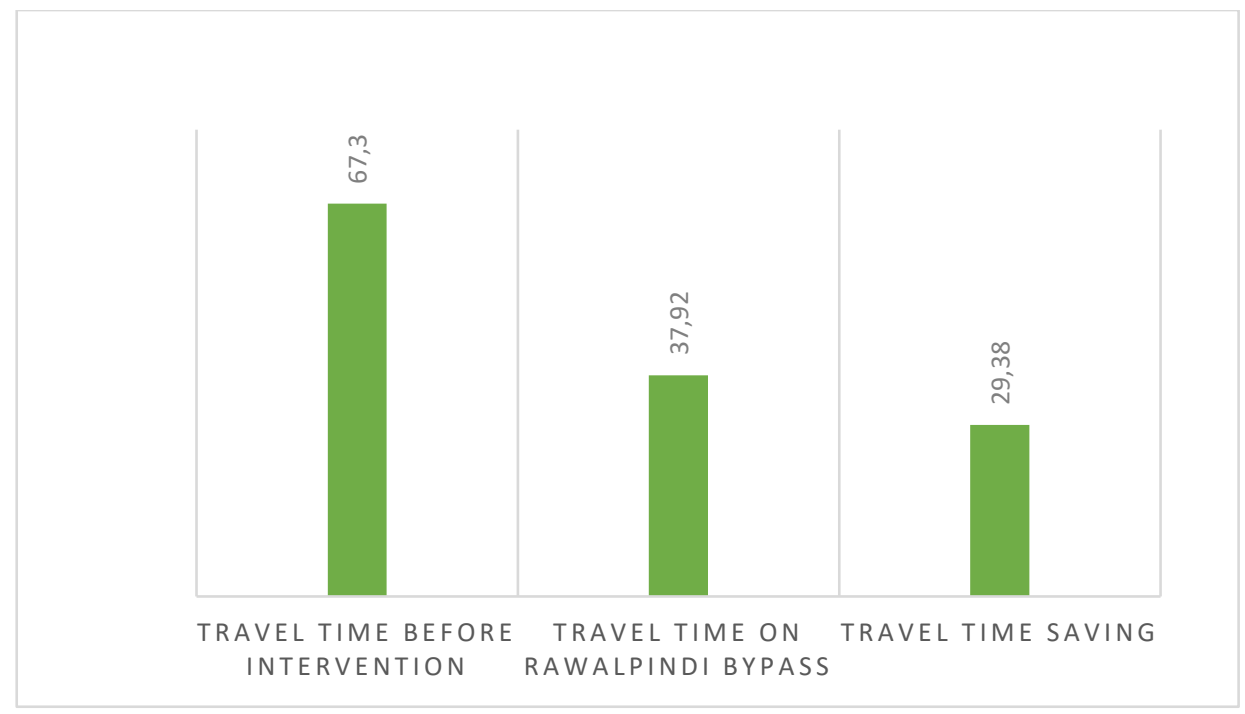

Travel Time Savings $=($ Occupancy of Vehicle $) \mathrm{X}$ (AADT X Travel Time Saved) $\mathrm{X}$ (Unit Travel Time Cost

From the analysis, it is concluded that 29.38 Mins per vehicle can be saved after the intervention. Now using the unit travel time cost for both car and trucks the total Monterey benefit was calculated which is PKR. 2.535 Million per day or PKR 923.5 Million per year.

\subsection{Safety Savings}

The World Health Organization has recognized the seriousness of traffic accidents in terms of fatalities, personal injuries and property damage as a social and public health problem. Transportation Projects either directly or indirectly reduce the crashes rates or severity. Enhancing the safety is considered as a key user benefits pertaining to the physical or policy changes in transportation system.

(Fatal Crashes + Non- fatal Crashes) Before Intervention - (Fatal Crashes + Non- fatal Crashes) After Intervention

Equation 3 is used to calculate total numbers of crashes saved after intervention. The Number of Fatal and Non-Fatal Crashes are calculated in for all of the above sections of highway taken for analysis purpose. Both rates are calculated by keeping in view without intervention \& with intervention scenario of RWP Bypass. The result of analysis is shown figure 7 below. The costs for fatal and nonfatal crashes 
are taken from iRAP - International Road Assessment Program which are as under. Using these costs total savings are calculated and results are shown in figure 8. It has been observed that after intervention PKR 291 Million can be saved per year as the no of fatal and non-fatal crashes are reduced.

\section{True Cost of Road Crashes}

- Fatality - 70 times GDP per capita

- Injury - 18 times GDP per capita

\section{For Pakistan:}

- Per capita income of Pakistan - $\$ 1250$

- Fatal Crash - \$87,500 (aprox. Rs.100,00,000.00)

- Injury Crash - $\$ 22,500$ (aprox. Rs.2,500,000.00)

Figure 7: Crash Rate Savings

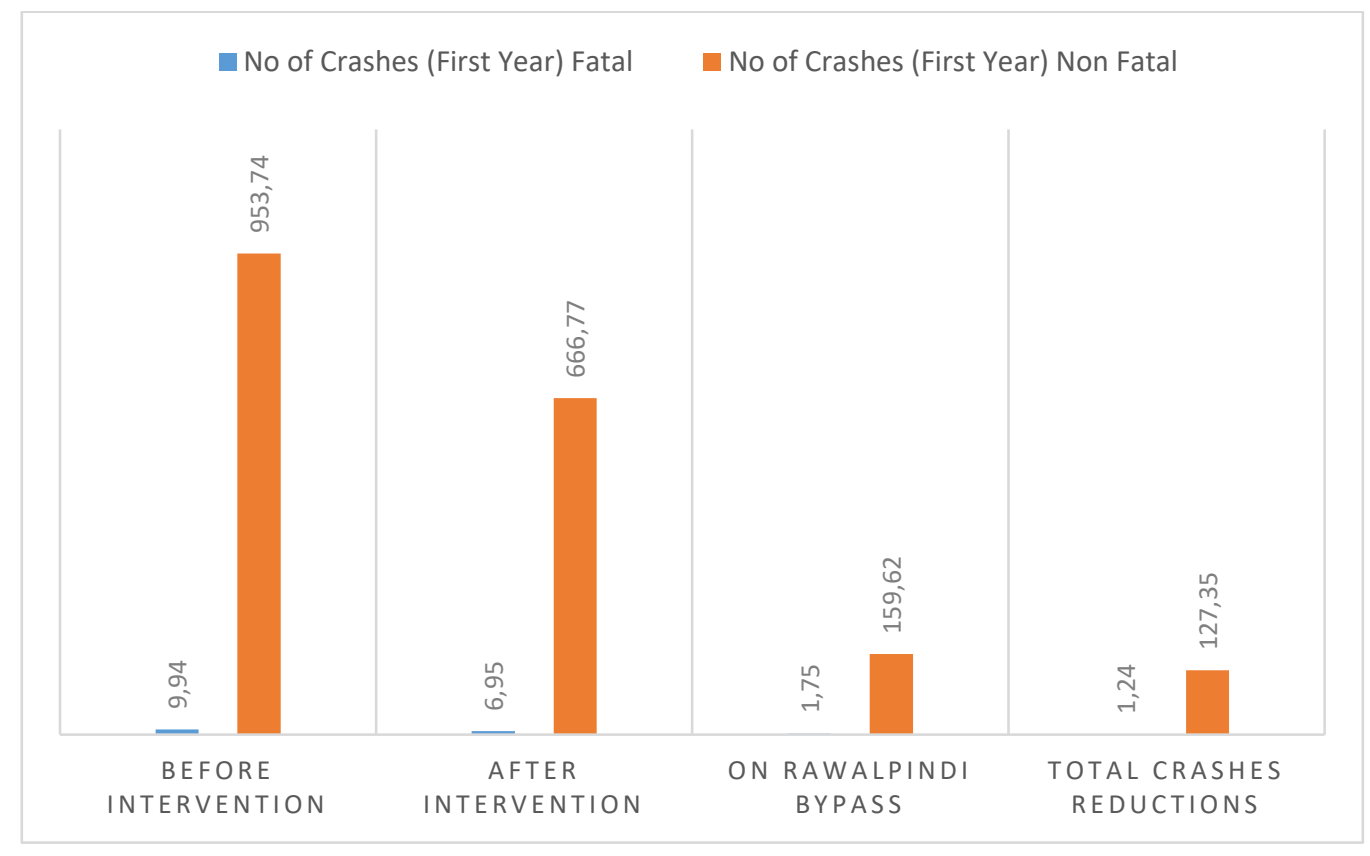

Figure 8: Total Crash Cost Savings per year (Rs. Millions)

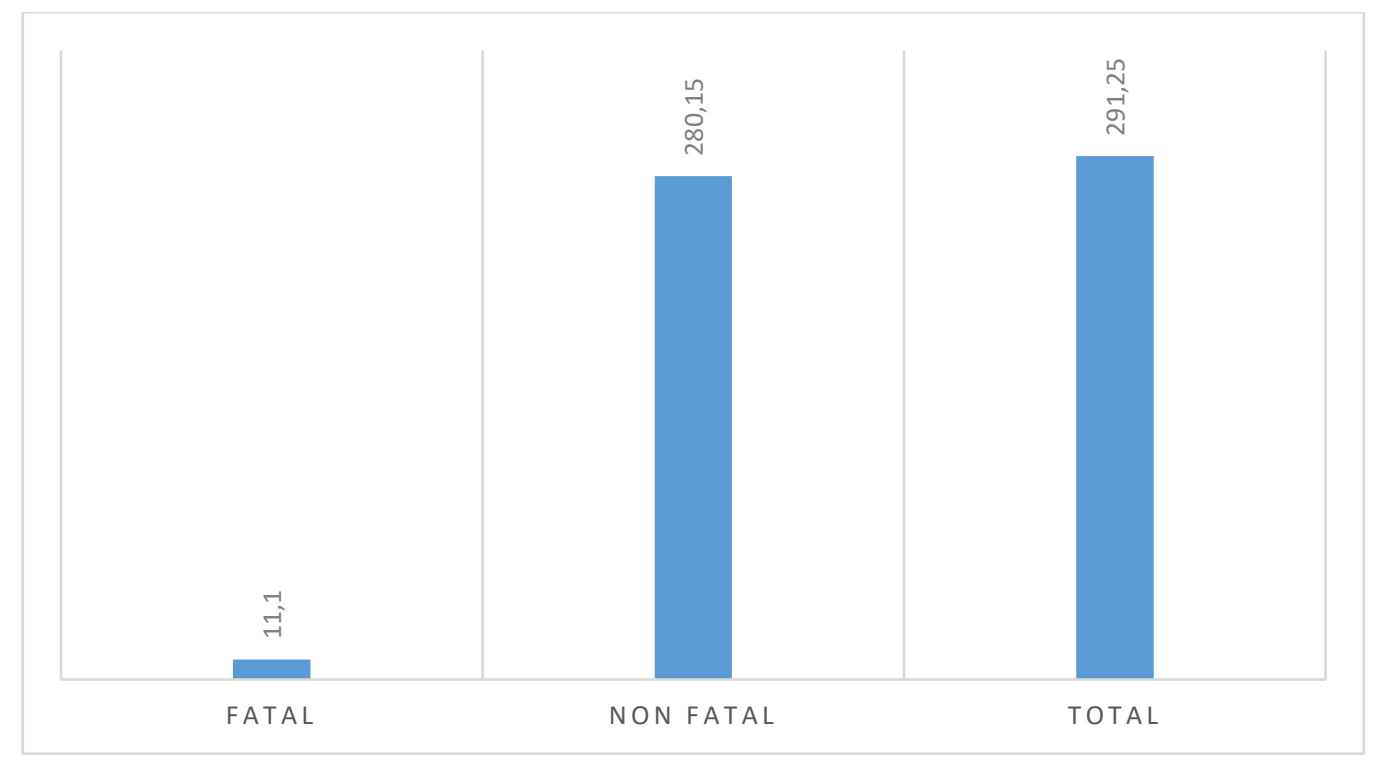




\subsection{Vehicle Operating Cost}

For the calculation of vehicle operating cost Rawalpindi bypass was considered as a case study. Rawalpindi by pass is supposed to be constructed to divert the traffic on N-5 from Taxilla to Rawat directly. The bypass will be 60 kilometers two-lane divided highway with grade separated roads on the intersections. Before the construction of bypass, the vehicles travel via two routes from Rawat to Taxila. These two routes directly pass through the city of Rawalpindi thus creating a lot of congestion on roads and increasing the vehicle operating cost. The vehicle operating cost calculation (VOC) was done by using the Hepburn model (Comsis,1999). The model considers speed and vehicle characteristics for the calculation of VOC. The Hepburn model is used for the calculation because the routes for which VOC is to be calculated has different variation of speed sections. After applying the methodology VOC before the intervention is first calculated. Results are shown in figure 9. The speed used for calculations was calculated using COMSIS method. The VOC savings are calculated using equation mentioned below

VOC User Saving $=[$ Principal Arterial w/o Intervention $]-[$ Principal Arterial with Intervention + Expressway/Bypass]

\section{Figure 9: VOC Savings (PKR. Millions)}

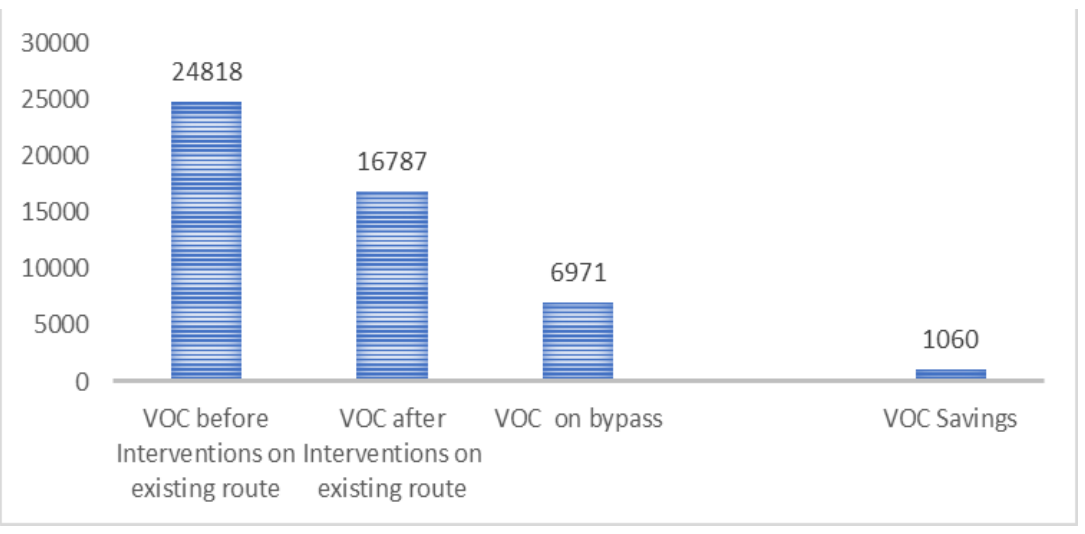

\subsection{Air Quality Impact}

In evaluating the impact of transportation improvements on air quality, the first step is to estimate the change in emissions as a result of changes in the average speed of vehicles, increases in motor vehicle trips, and increases in VMT due to these improvements (Williams, 2007). The second step is to determine the resulting change in pollutant concentrations due to the change in emissions. Total reduced emissions are calculated by using the equation.

Reduced Emissions = (Emissions before Interventions $)-($ Emissions on Existing Route with Bypass + Emissions on Bypass

Figure 10: Reduction in Emissions after intervention

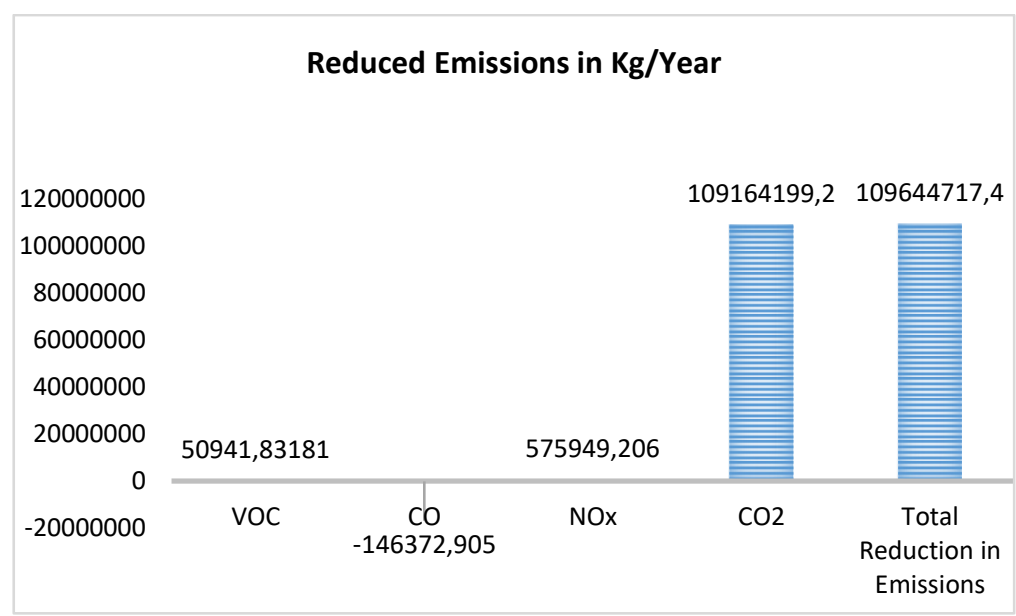




\section{Multi Criteria Decision Making (MCDM)}

Multiple criteria decision making (MCDM) refers to making decisions in the presence of multiple, usually conflicting, criteria. MCDM problems are common in everyday life. Author have evaluated project cost, travel time benefits, safety benefits, vehicle operating cost benefits and reduced emissions. On the basis of these performance criteria we have different alternatives and then we select which one is better through multi criteria analysis. After all performance criterions have been weighted and scaled, the challenge remains to combine the impacts for each alternative. In this amalgamation step an appropriate operation is used to yield a combined level of desirability for each alternative so that the best choice can be identified. Several tools and techniques are employed for amalgamation such as mathematical value, or utility functions rating and ranking and cost effectiveness. Figure 6 is showing the steps followed by author for MCDM. The key Performance criteria which author have used for MCDM are, project initial, travel time saving, safety, vehicle operating, crash rate savings cost in Millions Rs while air quality impact as reduced emissions in Mg. It is sought to use Analytical Hierarchy Process to assign relative weights to all the above key performance criteria. Pair wise comparison matrix is obtained by taking survey. The survey involves different questions asked from professionals about their perception of importance of these mentioned criterions.

\begin{tabular}{|c|c|c|c|c|c|}
\hline & Project Cost & TT Saving & Crash Savings & $\begin{array}{c}\text { VOC } \\
\text { Savings }\end{array}$ & Reduced Emission \\
\hline Project Cost & 1 & 3 & $1 / 2$ & 5 & 3 \\
\hline TT Saving & $1 / 3$ & 1 & $1 / 3$ & 2 & $1 / 3$ \\
\hline Crash Rate & 2 & 3 & 1 & 5 & 5 \\
\hline Savings & & & & & \\
\hline VOC Savings & $1 / 5$ & $1 / 2$ & $1 / 5$ & 1 & $1 / 5$ \\
\hline Emission & $1 / 3$ & 3 & $1 / 5$ & 5 & 1 \\
\hline
\end{tabular}

The above matrix has shown that Crash Savings is the most important criterion among all other criterions. After crash rate project cost, travel time, reduced emissions and VOC savings are taken.

Where 1 Refers to Criterion $\mathrm{X}$ is Equally Important to Criterion $\mathrm{Y}, 1 / 5$ Refers to when Criterion $\mathrm{X}$ is Strongly less Important than Criterion Y, $1 / 3$ Refers to when Criterion $X$ is Moderately less Important than Criterion Y, 1/2 Refers to when Criterion X is slightly less Important than Criterion Y, 5 Refers to when Criterion X is Strongly More Important than Criterion Y, 3 Refers to when Criterion X is Moderately More Important than Criterion $\mathrm{Y}$ and 2 Refers to when Criterion $\mathrm{X}$ is slightly More Important than Criterion Y. The normalized weights of each criterion are given below.

\section{Table 6: Normalized Weights}

\begin{tabular}{lc}
\hline Performance Criterion & Normalized Weights \\
\hline Project Cost & 0.2722 \\
TT Saving & 0.0951 \\
Crash Rate Savings & 0.4107 \\
VOC Savings & 0.0531 \\
Emission & 0.1689 \\
\hline
\end{tabular}

After normalized weights obtained now consistency check is applied to check the randomness of the matrix using equation given below

$$
A * w=\lambda \max * w
$$

The Eigen vector $(\mathrm{w})$ corresponding to the eigen value $\lambda \max$ in the above matrix equation is given as;

$W=\left|\begin{array}{l}0.2722 \\ 0.0951 \\ 0.4107 \\ 0.0531 \\ 0.1689\end{array}\right|$


The Consistency ratio is then determined using the equation below and it is observed that the consistency ration is 0.082 which is less than 0.1 so it is acceptable.

Scaling is used to Establishment of common unit or scale of measurement so that all performance criterions can be express in commensurate units. Risk scenario method is used for scaling (Certainty Equivalent Approach). The levels for each criterion is taken from bypass calculations relative to each alternative and shown in table 7.

Table 7: Savings Criteria Levels for Each Criterion

\begin{tabular}{lccccc}
\hline \multicolumn{5}{c}{ Criteria Level as Per Alternative } \\
Alternative & $\begin{array}{c}\text { Project Cost (Rs. } \\
\text { Millions) }\end{array}$ & $\begin{array}{c}\text { TT Savings } \\
\text { (Rs.Millions) }\end{array}$ & $\begin{array}{c}\text { Crash Rate } \\
\text { Savings } \\
\text { (Rs.Millions) }\end{array}$ & $\begin{array}{c}\text { Voc Savings } \\
\text { (Rs.Millions) }\end{array}$ & $\begin{array}{c}\text { Reduced } \\
\text { Emission } \\
\text { (Tons) }\end{array}$ \\
\hline A (Do Nothing) & 0 & 0 & 0 & 0 & 0 \\
B (60 km) & 41000 & 923.45 & 291.25 & 1060.56 & 109644 \\
C (51 km) & 33800 & 1022 & 346.30 & 2107 & 144271 \\
\hline
\end{tabular}

Now the procedure to find utilities using Certainty Equivalent Approach is given below.

\section{Single-Criterion Utility Function for Project Cost}

Upc $(41000 \mathrm{M})=0$ (Worse)

Upc $(0 \mathrm{M})=100$ Best

Assume that Decision Makers consider Rs.20000 Million as indifference point

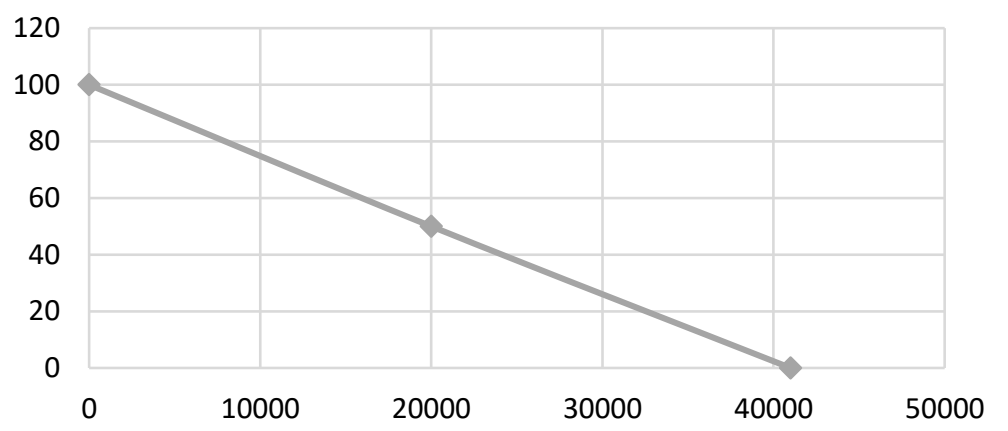

PKR. Millions

\section{Single Criteria Utility Function for TT Savings (Rs. Millions)}

Utt $(0)=0$ (Worse)

$\mathrm{Utt}(1022)=100$ (Best)

Assume that Decision Makers consider Rs. 500 Million as indifference point

This Indicates Risk Taker Behavior

\section{Single Criteria Utility Function for Crash Savings (Rs.Millions)}

Ucr $(0)=0$ (Worse )

Ucr $(346.30)=100$ (Best)

Assume that Decision Makers consider Rs. 190 Million as indifference point

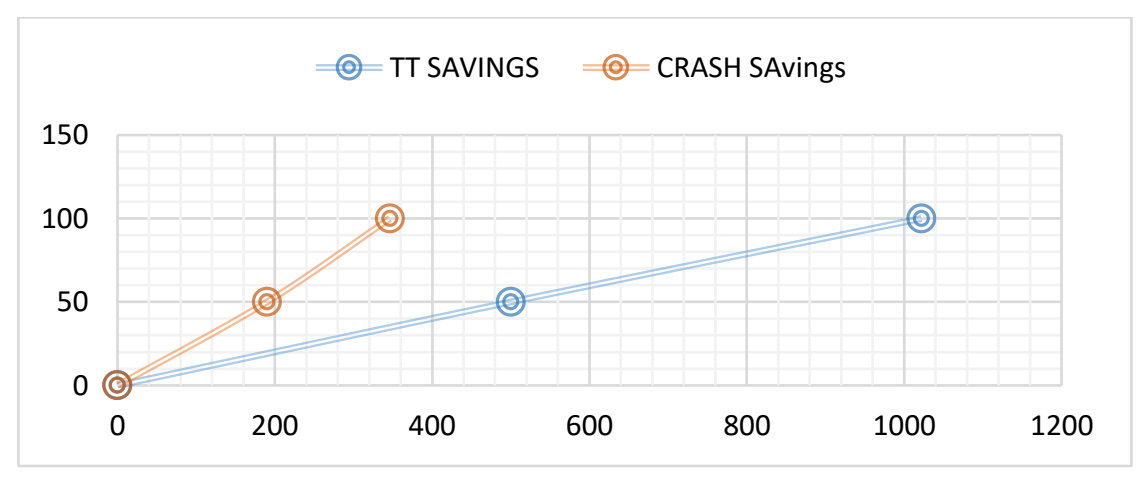

PKR. Millions 


\section{Single Criteria Utility Function for VOC Savings (Rs. Millions)}

Uvoc $(0)=0$ (Worse )

$\operatorname{Uvoc}(2107)=100$ Best

Assume that Decision Makers consider 765 Million as indifference point

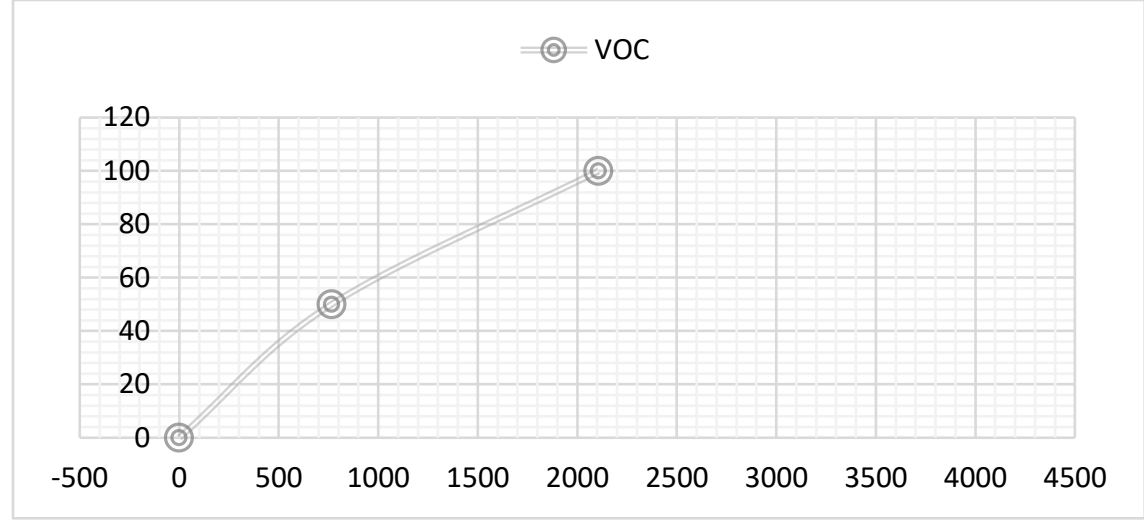

PKR. Millions

\section{Single Criteria Utility Function for Reduced Emissions (Tons)}

Ure $(0)=0$ (Worse )

Ure $(144271)=100$ Best

Assume that Decision Makers consider $70000 \mathrm{Mg}$ as indifference point

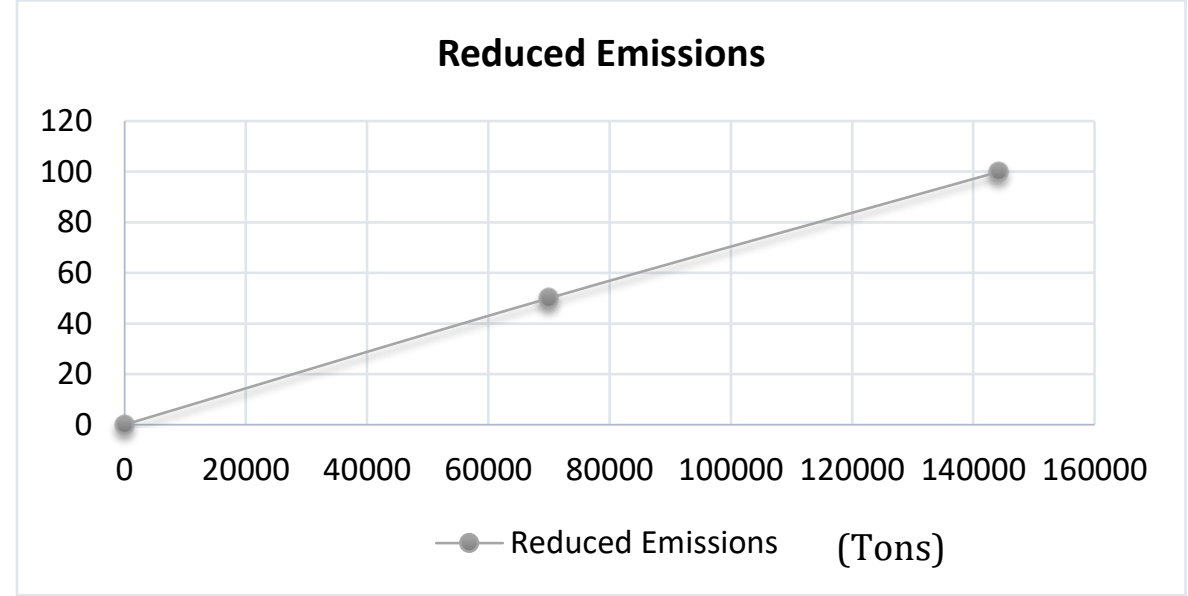

All the above-mentioned graphs are plotted by taking values of performance criterion on $\mathrm{X}$ axis while utility on Y axis. After plotting graphs, the scales of other performance criterion are hence measured. Each graph shown some functions of utilities with respect to the level of each performance criterion. The selection of best alternative using the additive utility function approach for amalgamation is calculated in the following table. Overall utility is the summation of each scaled values of a criterion multiplied with its respective normalized weights. This step involves the amalgamation or combination of all scaled and weighted performance criteria to determine the overall outcome of a transportation alternative and therefore to choose the best alternative. Scaled values for each performance criterion are shown in table 8 below.

\section{Table 8: Scaled Values for Each Performance Criteria}

\begin{tabular}{|c|c|c|c|c|c|}
\hline & \multicolumn{5}{|c|}{ Scaled Value } \\
\hline Alternative & $\begin{array}{l}\text { Project Cost } \\
\text { (Rs.Millions) }\end{array}$ & $\begin{array}{l}\text { TT Savings } \\
\text { (Rs. Millions) }\end{array}$ & $\begin{array}{l}\text { Crash Sav } \\
\text { (Rs. Millions) }\end{array}$ & $\begin{array}{l}\text { VOC } \\
\text { (Rs.Millions) }\end{array}$ & $\begin{array}{c}\text { Savings } \\
\text { Eeduced } \\
\text { Emission } \\
\text { (Tons) }\end{array}$ \\
\hline$A$ & 100 & 0 & 0 & 0 & 0 \\
\hline B & 0 & 90 & 85 & 63 & 74 \\
\hline $\mathrm{C}$ & 18 & 100 & 100 & 100 & 100 \\
\hline
\end{tabular}

The overall utility of each alternative is calculated by using the equation below 
Utility = W (PC) x SC (PC) + W (TT) $x$ SC (TT) + W (CR) x SC (CR) + W (VOC) x SC (VOC) + W (Emission) $\mathrm{x}$ SC (Emission)

Where

$\mathrm{W}=$ Normalized Weight of Criterion

Figure 11: Overall Utility Ranking for all three alternatives

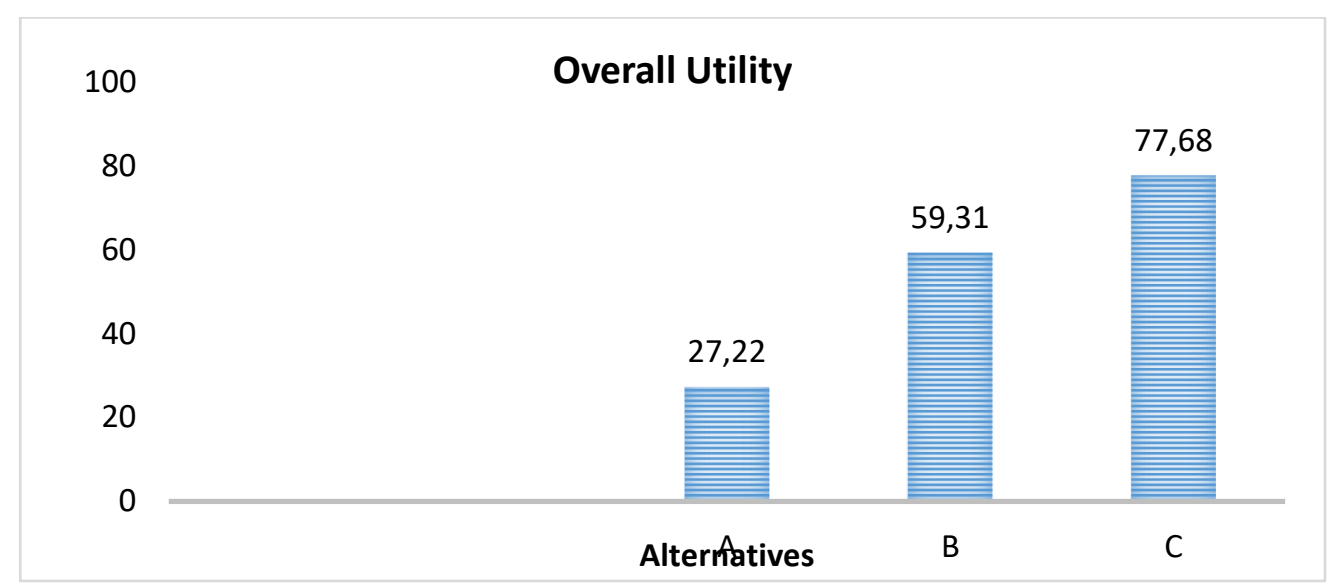

\section{Conclusions}

The core of transportation decision making is the evaluation of transportation projects and programs in the context of available funding. For this reason, the principles and procedures of transportation project evaluation and programming are of interest to transportation engineers and planners, transportation agency administrators, facility managers and service providers, environmental groups, and the general public. This is a critical issue for governments everywhere. Each year, several trillions of dollars are invested worldwide in transportation facilities with a view to enhancing transportation system mobility, security, and safety, and to spurring economic development while minimizing environmental and other adverse impacts. Same is the case within Pakistan. This study provides indications of good practices that could be followed in the evaluation of alternatives transportation systems for the purpose of decision making, on the ground of demand estimation and Traffic on different segments, Travel Time Saving and Analysis that proved to be 2.535 Million PKR per day or 923.5 Million PKR per year, the Safety Cost Savings were around 292 Million PKR per year, the Vehicle Operating Saving Cost proved to be 1060 Million PKR per year. Similarly, the total Emission Reduction was around 1096447 Tons/Year.

The techniques that can be used to make decisions when there are multiple criteria with different dimensions, both monetary and non-monetary. The first task in multiple criteria evaluation is to assess how decision makers attach relative levels of importance (or weights) to these criteria. The study includes the review of Multi-Criterion Evaluation and Decision Making; carried out in accordance with pair-wise comparison performance, in which Analytical Hierarchy Process (AHP) was used to weight the corresponding alternatives. The next task in multi criteria evaluation is scaling where each criterion is converted from its original dimension to one that is uniform and commensurate across all performance criteria. In economic efficiency evaluation, for instance, the required common metric of measurement is monetary (Pakistani Rupees), and therefore performance criteria such as travel time, safety, and vehicle operating cost are expressed in monetary value. The value function approach is adopted when the decision making is carried out under the certainty scenario, whereas the utility function approach is used when the decision making is being carried out under the risk scenario. These scenarios and their various approaches to scaling. Finally, the study incorporates following conclusions which are given as under.

1. Rawalpindi Bypass will surely be reducing congestion on both case scenarios under consideration (base-case scenario and alternative scenarios both). 
2. Rawalpindi Bypass's saving vehicle operating cost is estimated to be 1060 Million per year in accordance with 2015 constant PKR.

3. Saving Travel Time and its Analysis showed 4380 hours /year with the cost of 924 Million PKR / year will be saved after making this asset operational.

4. The Emissions Reduction is proved at 299 Tons/day.

5. The estimated Safety Cost Savings are around 292 Million PKR per year in this study.

6. This study provides indications of good practices that could be followed in the evaluation of alternatives transportation systems for the purpose of decision making.

7. Based on overall utilities, the alternative $C$ which is Rawalpindi Bypass with $51 \mathrm{Km}$ is best. The result shows that this alternative is best as compared to other alternatives based on criteria defined.

\section{Citation information}

Shakir, M. K., Khurshid, M. B., Iqbal, J., \& Adeel, M. (2018). Multicriteria Decision Making (MCDM) for evaluation of different transportation alternatives: A case of Rawalpindi bypass Pakistan. Journal of Sustainable Development of Transport and Logistics, 3(3), 38-54. doi:10.14254/jsdtl.2018.3-3.3.

\section{References}

AASHTO. (2003). A Manual of User Benefit Analysis for Highways. 2nd Edition American Association of State Highway and Transportation Officials, Washington, D.C.

COMSIS Corporation, Scientific Applications International Corporation, Garman Associates. (1995). Development of diurnal traffic distribution and daily, peak and off-peak vehicle speed estimation procedures for air quality planning, Work Order B-94-06, Federal Highway Administration, U.S. Department of Transportation, Washington, DC.

Engineer Estimate of Hasanabdal-Havelian Section E-35.

Gwilliam, K. M. (1997). The value of time in economic evaluation of transport projects: Lessons from recent research. World Bank (Washington DC).

Planning Commission. (2004). Rawalpindi Bypass PC1.

Sinha, K. C., \& Labi, S. (2011). Transportation decision making: Principles of project evaluation and programming. John Wiley \& Sons.

Transportation Research Board. (2000). Highway Capacity Manual 2000. Transportation Research Board, Washington, D.C.

Williams-Derry, C. (2007). Increases in greenhouse-gas emissions from highway-widening projects. Sightline Institute, October.

World Health Organization (WHO). (2004). World Report on Road Traffic Injury Prevention. Washington, DC.

$\mathrm{Xu}, \mathrm{L} ., \quad \&$ Yang, J. B. (2001). Introduction to multi-criteria decision making and the evidential reasoning approach (pp. 1-21). Manchester: Manchester School of Management.

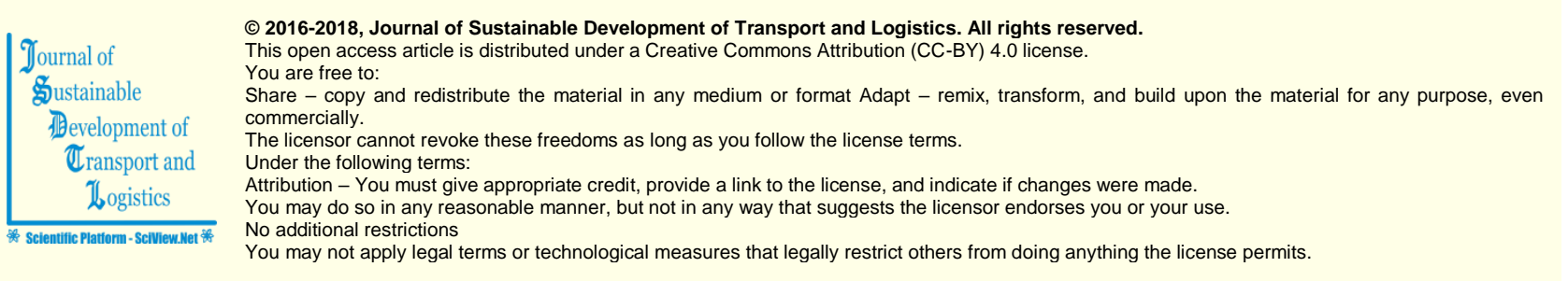

Journal of Sustainable Development of Transport and Logistics (ISSN: 2520-2979) is published by Scientific Publishing House "CSR", Poland, EU and Scientific Publishing House "SciView", Poland, EU

Publishing with JSDTL Publ

Publishing with JSDTL ensures:

- High visibility and discoverability via the JSDTL website

- Rapid publication

- Rapid publication

- Discounts and waivers for authors in developing regions

Submit your manuscript to a JSDTL at https://jsdtl.sciview.net/ or submit.jsdtI@sciview.net 